Balley, R. W. \& OXFoRd, A. E. (1958). J. gen. Microbiol. 19, 130-145

\title{
A Quantitative Study of the Production of Dextran from Sucrose by Rumen Strains of Streptococcus bovis
}

\author{
By R. W. BAILEY AND A. E. OXFORD \\ Plant Chemistry Division, D.S.I.R., Palmerston North, New Zealand
}

SUMMARY : Freshly isolated and old stock strains of Streptococcus bovis originating from the rumen will produce dextran at $37^{\circ}$ in liquid sucrose-containing media. For good yields the presence of $\mathrm{CO}_{2}$ in some form is necessary. The $\mathrm{CO}_{2}$ may be provided as $\mathrm{HCO}_{3}^{-}$at the start or during the life of the culture or by incubation in a $\mathrm{CO}_{2}$ atmosphere. The dextran has $[\alpha]_{\mathbb{D}}^{20}+187^{\circ}$ to $+190^{\circ}$ and is similar chemically to the leuconostoc dextran save that branching of the $\alpha 1 \rightarrow 6$ linked anhydro-glucose chain is rarer. With some strains practically no dextran is formed in $\mathbf{H}_{2}$ as gas-phase or in a closed system without $\mathrm{HCO}_{3}^{-}$from which air is excluded. Other strains seem to have a limited power of producing dextran under these conditions, possibly because their action is not entirely homofermentative. Tween 80 will partially replace $\mathrm{CO}_{2}$ even with the first kind of strain. Highest yields of dextran, up to $80 \%$ of the anhydroglucose provided, are obtained when the life of the culture is prolonged by repeated neutralization and when additional sucrose is supplied. This is best achieved by the continuous neutralization obtained when solid $\mathrm{CaCO}_{3}$ is present in the culture. Dextran production is always accompanied by accumulation of fructose in the culture liquid together with a reducing fructose-containing disaccharide. Dextran can sometimes be produced in a simple liquid sucrose + proteose peptone medium with no phosphate buffering. Other things being equal, the presence of $\mathrm{CO}_{2}$ or $\mathrm{HCO}_{3}^{-}$does not greatly increase the yield of bacterial protein in sucrose media.

Streptococcus bovis or a similar amylolytic group D streptococcus is always present in the rumen (see MacPherson, 1953; Hungate, 1957). Strains of this organism have been reported to produce at least two types of polysaccharide: a capsular polysaccharide and a water-soluble polyglucosan. The capsular polysaccharide contains galactose, rhamnose and uronic acid units (Hobson \& MacPherson, 1954) and is produced in media which contain glucose or presumably any other fermentable carbohydrate. There is no requirement of $\mathrm{CO}_{2}$ for its formation and in older cultures it may also be found free in solution although admittedly in very low concentrations. As the capsular compound does not contain glucose there should be no difficulty in determining which of the two types of polysaccharide is responsible for the sliminess of any given S. bovis culture.

Hehre \& Neill (1946) showed, chiefly by serological tests, that many strains of 'viridans' streptococci isolated from the blood of patients with subacute bacterial endocarditis could convert sucrose into a polysaccharide indistinguishable from leuconostoc dextran. Streptocococcus bovis is in many respects also a 'viridans' streptococcus (Topley \& Wilson, 1946). Niven, Smiley \& Sherman (1941) originally stated that several strains of $S$. bovis, of unrecorded origin, produced from sucrose a soluble polysaccharide which was described as 'dextran' because it yielded glucose on hydrolysis. More recently, Dain, 
Neal \& Seeley (1956) reported that the generality of $S$. bovis strains, including those isolated from cattle rumen, formed large glucosan-containing mucoid colonies (as distinct from the usual non-mucoid pinhead 'typically streptococcal' colonies) on nutrient agar only when provided with sucrose and a carbon dioxide atmosphere. The polysaccharide was shown to be a polyglucosan but the major linkage and hence the polysaccharide was not identified. In corresponding liquid cultures they stated that 'the cells tended to remain in suspension even after several days and viscosity of the medium was increased although in no case did complete solidification occur.' Hence these authors did not show that the organism is capable of producing the polyglucosan in liquid media nor that the polyglucosan produced on agar is dextran. In contrast to the above work Dr J. C. Appleby, formerly of the Rowett Research Institute, informed us that in $\mathbf{1 9 5 6}$ she isolated from two sheep rumens a strain of $S$. bovis which produced much polyglucosan on sucrose nutrient agar in a hydrogen atmosphere. There was apparently no stimulation of polyglucosan production by $\mathrm{CO}_{2}$. It seems likely therefore that such strains are not uncommon.

Most of the work on dextrans has hitherto been done on material produced by Leuconostoc spp. Following these investigations dextrans may be defined as water-soluble polyglucosans in which the major linkage is the $\alpha \mathbf{1} \rightarrow \mathbf{6}$ glucosidic link (see Barker et al. 1955). Varying proportions (0-20\%) of $\alpha 1 \rightarrow 3$ and $\alpha 1 \rightarrow 4$ glucosidic linkages have been reported to be present in the dextrans produced by different Leuconostoc spp. (Jeanes \& Wilham, 1952; Barker et al. 1954). These secondary linkages are believed to occur as branch points along the main chain of $\alpha \mathbf{1} \rightarrow \mathbf{6}$ linked glucose units. The presence of the $\alpha 1 \rightarrow 6$ glucosidic link, as the major linkage, must be demonstrated to show that any polyglucosan is in fact dextran.

Leuconostoc spp., which, unlike Streptococcus bovis, are heterofermentative (i.e. $\mathrm{CO}_{2}$ producers) require neither added $\mathrm{CO}_{2}$ in the gas phase nor $\mathrm{HCO}_{3}^{-}$to give good dextran yields from sucrose-containing liquid media. It seemed therefore desirable to establish whether $\mathrm{CO}_{2}$, in some form, was necessary for dextran production by $S$. bovis, particularly in liquid media. It also appeared necessary to show clearly to what extent the polysaccharide resembled true leuconostoc dextran. Such results are of practical interest since in the rumen $S$. bovis lives in a bicarbonate buffer in the presence of a gas-phase containing $\mathrm{CO}_{2}$. When the animal consumes a sucrose-containing ration such as spring grass or clover the organism may produce a dextran slime. Hungate, Fletcher, Dougherty \& Barrentine (1955) in fact believed that slime production in the rumen 'may be associated in an important way with bloat in ruminants'.

In this paper we show that dextran, produced from sucrose only, is responsible for the greatly increased viscosity of suitable liquid cultures of rumen strains (old and freshly isolated) of Streptococcus bovis. There is an absolute requirement for $\mathrm{CO}_{2}$ to give appreciable dextran production by most, but not all, strains of this organism no matter how highly the medium may be buffered by phosphates, etc. We also record preliminary observations on the structure of the $S$. bovis dextran and on the nature of the soluble sugars found 
in high dextran-producing cultures. An account of the properties of $S$. bovis dextransucrase is reserved for a subsequent publication. For the purpose of the present paper it has been considered sufficient to show that the polymer is a polyglucosan and that the major linkage present is the $\alpha \mathbf{I} \rightarrow 6$ glucosidic linkage. This has been done by the chromatographic identification of isomaltose in partial hydrolysates and glucose in total hydrolysates of the dextran. Further confirmation has been obtained by periodate oxidation and by measurements of $[\alpha]_{\mathbb{D}}$ values.

\section{METHODS}

Strains of rumen Streptococcus bovis and of Leuconostoc mesenteroides

Old stock cultures. Seven strains of Streptococcus bovis were obtained, freeze dried, from the Rowett Research Institute, Bucksburn, Aberdeenshire, Scotland. They had been isolated from the rumen of sheep and calves in work described by Macpherson (1953); Mann, Masson \& Oxford (1954); Mann \& Oxford (1955). Their reference numbers are 18/C2, 18/M2, 19/C 1, 2B, 16 B, 2SA, and $1010 \mathrm{Y}$.

Freshly isolated strains of Streptococcus bovis. These were isolated from muslinstrained rumen liquor obtained from three fistulated cows feeding on rye grass or red clover at this laboratory. Two isolation procedures were used.

(1) A loopful of a $1 / 2500$ dilution of rumen liquor in sterile $0.5 \%(w / v)$ yeast extract (Difco) was inoculated into liquid $2 \%(\mathrm{w} / \mathrm{v})$ sucrose Bactothioglycollate medium (10 ml., Difco; containing $0.075 \%(w / v)$ agar but no glucose) and incubated for 1 day in air at $37^{\circ}$. A loopful of the shaken culture was streaked on several plates of $3 \%(w / v)$ sucrose $+3 \%(w / v)$ proteose peptone no. 3 (Difco) agar and the plates incubated at $37^{\circ}$ for 1 day in $\mathrm{CO}_{2}$ (see below). The first plate invariably showed confluent mucoid growth but single well-separated mucoid colonies were always found on the other plates. No other organisms were ever encountered under these conditions.

(2) Crude rumen liquor was centrifuged for $30 \mathrm{~min}$. at $40,000 \mathrm{~g}$, and $0^{\circ}$. The supernatant fluid was discarded. One small loopful $(0.001 \mathrm{ml}$.) of the yellow slimy layer on the surface of the centrifuged solid was inoculated into the sucrose + thioglycollate liquid medium (10 ml., above). Two successive serial dilutions were prepared by transferring 2 large loopfuls $(0.02 \mathrm{ml}$.) through 2 samples $(10 \mathrm{ml}$.) of sucrose + thioglycollate liquid medium containing $\mathbf{0 . 0 7 5} \%(\mathrm{w} / \mathrm{v})$ agar. After incubation at $37^{\circ}$ with $\mathrm{CO}_{2}$ as gas phase the final dilution almost invariably showed a few discrete growths of Streptococcus bovis which were purified by plating as above. Plating on the sucrose+ proteose peptone agar in $\mathrm{CO}_{2}$ always produced mucoid colonies whereas with sucrose + Brewer's anaerobic agar (Difco, no glucose or methylene blue) the colonies were often non-mucoid. No explanation is offered for this fact, and buffering the medium with phosphate did not alter it.

Nine new strains of Streptococcus bovis were thus isolated, denoted I (cow I); A1, A 2, 293C, 30 and 34 (cow 293); and IV, 40 and 44 (cow 294). Strains I, A1, A 2, and IV were obtained when the cows were on a diet of pure rye grass (Lolium species) and the other strains when they were on a diet of pure red 
clover (Trifolium pratense). For the main quantitative experiments $\boldsymbol{S}$. bovis strains $1010 \mathrm{Y}$ (old) and I (new) were used. All cultures were maintained in Difco tomato juice agar or in $\mathbf{0 . 2 5} \%$ sucrose + thioglycollate (Difco) agar stabs kept at $0^{\circ}$.

Leuconostoc strains. For comparative purposes a culture of Leuconostoc mesenteroides (NCIB 8590) was obtained from the National Collection of Industrial Bacteria (D.S.I.R.), Teddington, Middlesex, England.

\section{Liquid media}

For dextran production. Cultures of Streptococcus bovis in $3 \%(\mathrm{w} / \mathrm{v})$ sucrose $+3 \%(w / v)$ proteose-peptone no. 3 (Difco) liquid medium without agar did not always yield dextran in a $\mathrm{CO}_{2}$ atmosphere; an exception with $S$. bovis strain IV is described below. The following modified Bacto-thioglycollate liquid medium was invariably successful. Its composition at three concentrations $(a<b<c)$ of phosphate buffer was $(\%, w / v)$ : Bacto-yeast extract, 0.5; Bactocasitone, 1.1, $\mathrm{t}$-cystine (dissolved separately in a little boiling $0 \cdot 1 \mathrm{~N}-\mathrm{HCl}$ ), 0.025; sodium thioglycollate, $0.03 ; \mathrm{K}_{2} \mathrm{HPO}_{4},(a) 0.45 ;(b) 0.54 ; \mathrm{Na}_{2} \mathrm{HPO}_{4}$ $12 \mathrm{H}_{2} \mathrm{O},(c) 1.2 ; \mathrm{KH}_{2} \mathrm{PO}_{4},(a) 0.15 ;(b) 0.18 ;(c) 0.20 ;\left(\mathrm{NH}_{4}\right)_{2} \mathrm{HPO}_{4}, 0.03$; sucrose, usually $8 ; \mathrm{pH} 7 \cdot 0$. All salts (except $\mathrm{K}_{2} \mathrm{HPO}_{4}$, British Drug Houses Ltd) were of Analar quality.

For an initial $\mathrm{pH}$ value between $\mathbf{7 \cdot 0}$ and $\mathbf{8 \cdot 0}$, ammonia solution (sp.gr. $\mathbf{0 . 9 1}$ ) was added, drop by drop, to give the desired value. Sucrose could safely be sterilized in solution in this basal medium; other sugars to replace sucrose were sterilized separately in concentrated aqueous solution. Basal medium free from $\mathrm{CO}_{2}$ and $\mathrm{HCO}_{3}^{-}$was obtained sterile by three successive steamings, not by autoclaving. In this case the medium nearly filled a conical flask (1 1.) carrying a rubber bung pierced with a piece of open glass tubing. After each steaming the flask was removed, cooled rapidly, and the outlet tube closed. After the final steaming the medium was rapidly dispensed into small sterile conical flasks (50 or $100 \mathrm{ml}$.) containing any required sterile supplements (see below), inoculated, and plugged. The inoculum was 1 loopful $/ 50 \mathrm{ml}$. medium, from an $18 \mathrm{hr}$. culture at $37^{\circ}$ in liquid $2 \%(\mathrm{w} / \mathrm{v})$ sucrose + Bactothioglycollate medium.

Capsulation of the bacteria. The presence of capsules was demonstrated by negative staining, with $0.25 \%(\mathrm{w} / \mathrm{v})$ nigrosine, of the washed bacteria obtained by centrifuging cultures $(5 \mathrm{ml}$.) at $15,000 \mathrm{~g}$.

\section{Cultural techniques}

Incubation techniques were designed to cover: (a) growth in the absence of $\mathrm{CO}_{2}$ or $\mathrm{HCO}_{3}^{-}$but in the presence of oxygen or hydrogen; $(b)$ anaerobic growth in the presence of controlled amounts of $\mathrm{HCO}_{3}^{-} ;(c)$ growth with a $\mathrm{CO}_{2}$ gas phase, with or without control of $\mathrm{pH}$ value; $(d)$ growth in the presence of $\mathrm{CaCO}_{3}$ giving continuous $\mathrm{CO}_{2}$ and $\mathrm{pH}$ control. All cultures were incubated at $37^{\circ}$ for a specified time. This incubation temperature was below that of the rumen $\left(40^{\circ}\right)$. Leuconostoc dextransucrase is rapidly destroyed at $40^{\circ}$ (Koepsell \& Tsuchiya, 1952) and it was therefore decided to incubate the 
Streptocococcus bovis strains a little below this temperature. In cultures incubated for more than 1 day where it was judged that good dextran production would occur, more sucrose was added every $24 \mathrm{hr}$. as a sterile solution (4 ml. of $\mathbf{2 5} \%$ (w/v) solution $/ 50 \mathrm{ml}$. of culture).

Growth in the absence of $\mathrm{CO}_{2}$ or $\mathrm{HCO}_{3}^{-}$. Conical flasks $(50 \mathrm{ml}$.) nearly filled with media were used. They were either closed with a rubber bung or fitted with a bung carrying an open tube filled with self-indicating soda-lime. Cultures were also grown in shallow layers of medium in cottonwool-plugged flasks. Growth under a hydrogen gas phase was done in cottonwool-plugged flasks within a metal anaerobic jar (see below). Tween 80 (Atlas Powder Co. N.Z.) at $1 \%(\mathrm{v} / \mathrm{v})$ was added to several of these cultures.

Growth in the presence of controlled amounts of $\mathrm{HCO}_{3}^{-}$. The cultures were grown in the conical flasks closed with rubber bungs. Before inoculation the calculated amount of heat-sterilized $\mathrm{K}_{2} \mathrm{CO}_{3}$ solution $(5 \cdot 4 \% \mathrm{w} / \mathrm{v})$ was added.

Growth in a $\mathrm{CO}_{2}$ atmosphere. This was carried out by placing the inoculated cultures, in cottonwool-plugged flasks, in a 4 l. metal anaerobic jar (Messrs Gallenkamp Ltd). Not more than 11 . of liquid was incubated at a time so that the weight of $\mathrm{CO}_{2}$ in the jar ( $>6 \mathrm{~g}$.) was sufficient, if all had dissolved in the liquid medium during incubation, to give a concentration at least $0 \cdot 1 \mathrm{~m}$ in the medium. Air was displaced by a stream of water-washed $\mathrm{CO}_{2}$, from a cylinder, for at least $30 \mathrm{~min}$. No special effort was made to free the $\mathrm{CO}_{2}$ from traces of oxygen.

Growth in the presence of $\mathrm{CaCO}_{3}$. The sterile medium was added to sterile finely divided $\mathrm{CaCO}_{3}(3 \mathrm{~g} . / 50 \mathrm{ml}$.) just before inoculation and the flask loosely plugged with cottonwool.

\section{Control of the $\mathrm{pH}$ value of the cultures}

The $\mathrm{pH}$ value of the growing cultures fell from $7 \cdot 0-7 \cdot 5$ to $4 \cdot 0-4.5 \mathrm{in} 24 \mathrm{hr}$. When required the $\mathrm{pH}$ value was adjusted, with sterile aqueous ammonia (sp.gr. 0.95 ), to $7 \cdot 0$ (or 6.7 if the buffering capacity was high) every $24 \mathrm{hr}$. This was done by the cautious addition of ammonia whilst checking the $\mathrm{pH}$ value with narrow range indicator papers (British Drug Houses Ltd) with aseptic precautions. The ammonia solution was previously sterilized by heating it to the boiling point, rapidly cooling, and repeating the process 3-4 times during $30 \mathrm{~min}$. Inoculation of this solution into sterile nutrient broth never showed growth when incubated at $37^{\circ}$ for 3 days. When it was desired to introduce $\mathrm{CO}_{2}$ or $\mathrm{HCO}_{3}^{-}$into the growing culture sterile $\mathrm{K}_{2} \mathrm{CO}_{3}(20 \%$, $\mathrm{w} / \mathrm{v}$ ) was used to adjust the $\mathrm{pH}$ value.

\section{Dextran estimation}

Qualitative detection. Soluble polysaccharide was detected by the addition of ethanol ( 4 vol.) to the supernatant fluid obtained after centrifuging the culture $(5 \mathrm{ml}$.) for $30 \mathrm{~min}$. at $13,000 \mathrm{~g}$. When dextran was present the solution yielded a heavy precipitate or a turbidity which readily flocculated after shaking for a few minutes. Cultures containing dextran were always opalescent. Uninoculated medium or clear culture fluid containing no dextran 
yielded, on adding ethanol, a turbidity which did not flocculate even after prolonged shaking.

Quantitative measurement of dextran. A volume $(50 \mathrm{ml}$.) of culture was centrifuged for $30 \mathrm{~min}$. at $13,000 \mathrm{~g}$ to remove bacteria. Very viscous cultures were diluted with an equal volume of water before centrifuging, whilst cultures containing $\mathrm{CaCO}_{3}$ were acidified with $2 \mathrm{~N}-\mathrm{H}_{2} \mathrm{SO}_{4}$ to remove calcium and to avoid the precipitation of calcium lactate by the ethanol. Dextran was precipitated from the centrifuged fluid by the slow addition of ethanol ( $2 \mathrm{vol}$. and then standing the mixture at $0^{\circ}$ overnight. The clear supernatant fluid was decanted and kept for paper chromatographic analysis. After draining, the precipitate was dissolved in water $(100 \mathrm{ml}$.), boiled for 3 min., recentrifuged, and reprecipitated with ethanol (2 vol.). The final precipitate was dissolved in water, centrifuged, and made up to volume (100 or $250 \mathrm{ml}$.) for analysis. After diluting a portion of the solution (1-5 ml.) to $100 \mathrm{ml}$. with water, dextran was determined by the anthrone method of Roe (1954), a carefully purified sample of the streptococcus dextran being used as a standard. The extinction value of the developed colour was measured, at $625 \mu$., on a Beckman model DU spectrophotometer with $1 \mathrm{~cm}$. thick optical cells. The yield of dextran was expressed as \% conversion of the available anhydroglucose of the sucrose to polymerized anhydroglucose (i.e. dextran). The medium itself, when submitted to the above analysis, gave no measurable amount of polysaccharide.

\section{Yield of bacteria}

The solid residue obtained from the first centrifugation of the culture (50 $\mathrm{ml}$.) was suspended in water $(70 \mathrm{ml}$.), thoroughly shaken and centrifuged for $30 \mathrm{~min}$. at 13,000 $\mathrm{g}$. The washed organisms were freeze-dried, weighed, and analysed for total-N by the micro-Kjeldahl method.

\section{Structural investigations on the dextran}

Purification of the dextran. Dextran solution obtained in the analytical procedure (above), was further purified to remove traces of associated protein. This was achieved by shaking the solution four times with an equal volume of chloroform + amyl alcohol $(2 \cdot 5: 1, \mathrm{v} / \mathrm{v})$ and centrifuging to remove the emulsion formed (Sevag, Lackman \& Smolens, 1938). The purified dextran was precipitated with ethanol ( $2 \mathrm{vol}$.), dissolved in water, centrifuged, dialysed overnight, freeze dried and finally dried under vacuum at $60^{\circ}$.

Hydrolysis of the dextran. Dextran $\left(20 \mathrm{mg}\right.$.) dissolved in $1.5 \mathrm{~N}-\mathrm{H}_{2} \mathrm{SO}_{4}(10 \mathrm{ml}$.) was heated for $9 \mathrm{hr}$. at $100^{\circ}$, neutralized $(3 \mathrm{~N}-\mathrm{NaOH})$ and diluted to volume (100 ml.). Reducing sugars were measured in the hydrolysate, as glucose, by the method of Shaffer \& Hartmann (1921). The results obtained were corrected by the factor given by Pirt \& Whelan (1951) for these conditions. For paper chromatographic analyses the hydrolysate was neutralized with solid $\mathrm{BaCO}_{3}$, filtered, and concentrated to $\mathbf{0 . 2} \mathrm{ml}$. Partial hydrolyses were carried out by heating as above for $1.5 \mathrm{hr}$.

Paper chromatographic analyses. These were prepared from the hydrolysates 
and ethanol supernatants, by the usual techniques and developed with either of the following solvents:

(a) The top layer of a mixture consisting of $n$-butanol, ethanol, water and ammonia (49, 10, 40 and $1 \%, \mathrm{v} / \mathrm{v}$; Barker et al. 1954).

(b) The top layer of a mixture containing ethyl acetate, water and pyridine (2:2:1 v/v; Jermyn \& Isherwood, 1949). Sugars were detected with the following sprays: silver nitrate (Trevelyan, Proctor \& Harrison, 1950), aniline hydrogen phthalate (Partridge, 1949), naphthoresorcinol (Partridge, 1948), $\beta$-indolylacetic acid (Heyrovsky, 1956), benzylamine + ninhydrin (Bayly \& Bourne, 1953).

\section{Periodate oxidation and optical rotation of the dextran}

Dextran (100 mg.) was oxidized and periodate consumption and formic acid production measured by the methods referred to by Bailey, Barker, Bourne \& Stacey (1957). Optical rotations were measured on solutions of dextran $(30 \mathrm{mg}$.) dissolved in $\mathrm{N}-\mathrm{NaOH}(10 \mathrm{ml}$.) with a Hilger polarimeter and a $1 \mathrm{dm}$. tube. Because of the opalescence of dextran solutions exact readings were difficult to obtain.

\section{RESULTS}

Fermentation and other reactions of the Streptococcus bovis strains

All 16 strains of Streptococcus bovis were catalase-negative, morphologically similar, Gram-positive cocci and were typical $S$. bovis in the sense of Mann \& Oxford (1955) in that all were amylolytic, and fermented raffinose and inulin but not mannitol. Only one strain (293C) fermented arabinose, causing a fall in $\mathrm{pH}$ to $4 \cdot 5$. No strain produced dextran, in the presence of $\mathrm{CO}_{2}$, from any simple sugar or oligosaccharide save sucrose. Fructose was fermented by strain I at least. All strains produced very similar mucoid colonies on $\mathbf{3} \%$ $(\mathrm{w} / \mathrm{v})$ sucrose $+3 \%(\mathrm{w} / \mathrm{v})$ proteose peptone No. 3 (Difco) agar on incubation for 1 day in a $\mathrm{CO}_{2}$ atmosphere at $37^{\circ}$ or $40^{\circ}$. All were homofermentative towards glucose even in the presence of Tween $80(1-3 \%)$ and brought about a decrease of $\mathrm{pH}$ to 4 or less in 1 day at $37^{\circ}$.

Capsulation of the bacteria. All of the strains of Streptococcus bovis, particularly in 3-day cultures with $\mathrm{pH}$ control, produced zoogleal masses of capsulated cocci in all of the cultures including those producing dextran. Leuconostoc mesenteroides also produced capsulated organisms, indistinguishable from those of $\boldsymbol{S}$. bovis, in sucrose-containing cultures.

\section{Qualitative observations on the need for $\mathrm{CO}_{2}$ to obtain good dextran} production in liquid media

Streptococcus bovis. All strains gave obvious dextran production in the $8 \%(w / v)$ sucrose + phosphates liquid medium (cf. p. 133) when incubated for 1 day in a $\mathrm{CO}_{2}$ atmosphere. It seemed to make little difference in this respect whether the surface/volume ratio of the liquid culture was large or small. The cultures became viscous and opalescent and a clean supernatant fluid could not easily be obtained by centrifuging. Another way of providing $\mathrm{CO}_{2}$ with- 
out using a $\mathrm{CO}_{2}$ atmosphere was to neutralize with $\mathrm{K}_{2} \mathrm{CO}_{3}$ after some growth had taken place with a consequent fall in $\mathrm{pH}$.

The preliminary results are summarized in Table 1 from which it will be seen that yields of dextran of over $50 \%$ of the theoretical were obtained and that phosphate buffering could be dispensed with (see strain IV, Table 1); presumably ammonium lactate acted as the buffer in the sucrose + proteosepeptone medium after some growth had taken place.

Table 1. Yields of dextran produced by various strains of Streptococcus bovis, in liquid media, in the presence of $\mathrm{CO}_{2}$

All media contained $8 \%(w / v)$ sucrose unless otherwise stated. Incubation was for 3 days at $37^{\circ}$. See p. 133 for composition of the medium.

\begin{tabular}{|c|c|c|c|c|}
\hline $\begin{array}{l}\text { S. bovis } \\
\text { strain }\end{array}$ & Medium & $\begin{array}{l}\text { Volume } \\
\text { (ml.) }\end{array}$ & Cultural conditions & $\begin{array}{l}\text { sion of avail- } \\
\text { able anhydro- } \\
\text { glucose) }\end{array}$ \\
\hline $\mathbf{A}_{\mathbf{I}}$ & Phosphate (a) & 100 & $\mathrm{CO}_{2}$ atm.; no neutralization & $0 \cdot 36(9 \cdot 49)$ \\
\hline $\mathbf{A}_{1}$ & Phosphate (b) & 100 & $\begin{array}{l}\mathrm{CO}_{2} \text { atm.; neutralized with } \\
\mathrm{K}_{2} \mathrm{CO}_{3} \text { after } 1 \text { day }\end{array}$ & $0.68(17 \cdot 94)$ \\
\hline $\mathbf{A}_{\mathbf{2}}$ & Phosphate (a) & 100 & $\mathrm{CO}_{2}$ atm.; no neutralization & $2 \cdot 55(67 \cdot 28)$ \\
\hline $\mathbf{A}_{2}$ & Phosphate (a) & 100 & $\begin{array}{l}\text { No } \mathrm{CO}_{2} \text { atm.; neutralized } \\
\text { with } \mathrm{K}_{2} \mathrm{CO}_{3} \text { after } 1 \text { and } \\
2 \text { days }\end{array}$ & $1 \cdot 75(46 \cdot 17)$ \\
\hline 18/M2 & Phosphate (b) & 75 & $\begin{array}{l}\mathrm{CO}_{2} \text { atm.; neutralized with } \\
\mathrm{K}_{2} \mathrm{CO}_{3} \text { after I day }\end{array}$ & $2 \cdot 12(83 \cdot 46)$ \\
\hline $293 \mathrm{C}$ & Phosphate (c) & 65 & $\mathrm{CO}_{2}$ atm.; no neutralization & $0 \cdot 67(27 \cdot 23)$ \\
\hline $\mathbf{I}$ & Phosphate (b) & 75 & $\mathrm{CO}_{2}$ atm.; no neutralization & $1 \cdot 29(50 \cdot 78)$ \\
\hline $1010 \mathrm{Y}$ & Phosphate (a) & 100 & $\begin{array}{c}\mathrm{CO}_{2} \text { atm.; neutralized with } \\
\mathrm{K}_{2} \mathrm{CO}_{3} \text { after } 1 \text { and } 2 \text { days }\end{array}$ & $1 \cdot 44(37 \cdot 99)$ \\
\hline IV & $\begin{array}{l}3 \% \text { sucrose }+ \\
3 \% \text { (w/v) pro- } \\
\text { teose-peptone } \\
\text { No. } 3 \text { (no } \\
\text { phosphate) }\end{array}$ & 200 & $\begin{array}{l}2 \text { days } \mathrm{CO}_{2} \text { atm.; neutralized } \\
\text { with } \mathrm{NH}_{4} \mathrm{OH} \text { and more suc- } \\
\text { rose }(8 \cdot 5 \mathrm{~g} .) \text { added after } \\
2 \text { days; } 3 \text { rd day in air }\end{array}$ & $4.00(50 \cdot 16)$ \\
\hline
\end{tabular}

In the complete absence of $\mathrm{CO}_{2}$, either in the closed full flask or in air under soda-lime, the results were not so clear cut. Some strains of Streptococcus bovis, e.g. I, 18/M2 consistently gave practically no dextran in 3 days (see, however, Table 3 for the effect of Tween 80 in substitution for $\mathrm{CO}_{2}$ with strain I), even though obvious growth had occurred in $6 \mathrm{hr}$. Other strains sometimes gave a good dextran production in the absence of $\mathrm{CO}_{2}$, even in a closed system with oxygen excluded, e.g. strains $293 \mathrm{C}, 34,40$. The results were not consistent, strain $293 \mathrm{C}$ for example giving no dextran in a closed system on another occasion. In every instance, however, the presence of $\mathrm{CO}_{2}$ either in the gas phase or in solution at $0.10 \mathrm{~m}$ did increase the yield of dextran. Shallow layer cultures in a $\mathrm{CO}_{2}$-free medium, incubated in air, invariably produced some dextran. All $S$. bovis strains can probably utilize oxygen to some small extent since even freshly isolated strains are facultative anaerobes. It was noted that cultures, even in nearly full flasks under soda-lime sometimes produced enough $\mathrm{CO}_{2}$ to change the colour of the bottom few $\mathrm{mm}$. of the sodalime layer. 
Leuconostoc mesenteroides (NCIB 8590). This organism differs from Streptococcus bovis in being markedly heterofermentative. In our hands it gave a quicker growth and dextran production from $4 \%(\mathrm{w} / \mathrm{v})$ sucrose medium, with half the phosphate buffering of $(a)(\mathrm{p} .133)$ at $29^{\circ}$ in either a closed system or $\mathrm{CO}_{2}$-free air, than in air or in a $\mathrm{CO}_{2}$ atmosphere not freed from oxygen. This may merely mean that the particular strain used was microaerophilic. The results were similar in all instances after 2-3 days of incubation. Gas production in the closed system cultures was very obvious.

\section{Minimum concentration of $\mathrm{HCO}_{\mathbf{3}}^{-}$required for good dextran production} with Streptococcus bovis strain I incubated in a closed system

The results summarized in Table 2 indicate that, with Streptococcus bovis, strain I, an initial $\mathrm{CO}_{2}$ concentration of at least $0.005 \mathrm{M}$ (as $\mathrm{HCO}_{3}^{-}$) was necessary for good dextran production when neither $\mathrm{CO}_{2}$ gas nor oxygen was provided. Results from a similar experiment with $S$. bovis strain 1010 Y were much

Table 2. Effect of $\mathrm{HCO}_{3}^{-}$concentration on the yields of dextran produced by Streptococcus bovis, strain I

Medium (c) p. $183 ; 50 \mathrm{ml}$. (containing $4 \mathrm{~g}$. sucrose) in a closed system; incubated for 2 days at $37^{\circ}$.

\begin{tabular}{|c|c|c|c|c|c|c|}
\hline \multirow[b]{2}{*}{$\begin{array}{c}\text { Initial } \\
\mathrm{K}_{2} \mathrm{CO}_{3} \\
(\mathrm{M})\end{array}$} & \multicolumn{2}{|c|}{ Yield of organism } & \multirow{2}{*}{$\begin{array}{c}\text { Dextran as } \\
\% \text { conversion } \\
\text { of available } \\
\text { anhydro- } \\
\text { glucose }\end{array}$} & \multicolumn{3}{|c|}{ Sugars in supernatant fluid at end } \\
\hline & $\begin{array}{c}\text { Dry wt. } \\
\text { (mg.) }\end{array}$ & $\begin{array}{c}\text { Protein } \\
(\mathbf{N} \times 6.25) \\
(\mathrm{mg} .)\end{array}$ & & Fructose & Sucrose & $\begin{array}{c}\text { Reducing } \\
\text { disac- } \\
\text { charide }\end{array}$ \\
\hline None & 58 & $29 \cdot 00$ & 4.76 & - & +++ & - \\
\hline 0.0004 & 71 & & & + & ++ & - \\
\hline 0.0017 & 89 & $41 \cdot 00$ & $16 \cdot 40$ & $+t$ & +++ & + \\
\hline 0.005 & 87 & $46 \cdot 00$ & $39 \cdot 15$ & +++ & +++ & + \\
\hline 0.014 & 90 & $42 \cdot 10$ & $50 \cdot 27$ & +++ & ++ & ++ \\
\hline 0.028 & No grc & owth & - & - & - & - \\
\hline
\end{tabular}

more erratic. This is one of the strains that does not seem invariably to need $\mathrm{CO}_{2}$ in some form for dextran production. Neither strain grew in phosphate medium $(c)$ in the presence of $0.028 \mathrm{M}-\mathrm{HCO}_{3}^{-}$, even though the initial $\mathrm{pH}$ was below 8; presumably the salt concentration was too high.

It was obviously necessary to show that the extra buffering power of the medium due to the addition of $\mathrm{K}_{2} \mathrm{CO}_{3}$ was not the cause of dextran production. Medium $(c)$ was therefore made a stronger phosphate buffer by the addition of $\mathrm{Na}_{2} \mathrm{HPO}_{4}, 12 \mathrm{H}_{2} \mathrm{O}(0.3 \% ; 0.008 \mathrm{M})$ and $\mathrm{KH}_{2} \mathrm{PO}_{4}(0.05 \% ; 0.004 \mathrm{M})$ without change of $\mathrm{pH}$ value. Parallel cultures of Streptococcus bovis strain I in medium (c) modified and unmodified (each neutralized with ammonia after 1 and 2 days) in the absence of $\mathrm{CO}_{2}$ in a closed system gave no qualitative reaction for dextran in either instance although growth was profuse. When the third day of incubation was in a $\mathrm{CO}_{2}$ atmosphere, however, there was good dextran production in each instance. 


\section{Minimum sucrose concentration necessary for dextran production in a $\mathrm{CO}_{2}$ atmosphere}

Five strains of Streptococcus bovis (A1, I, 293C, 1010Y, IV) all behaved similarly in that no dextran was detected qualitatively in liquid thioglycollate medium $(c)$ cultures containing initially $0 \cdot 25 \%(\mathrm{w} / \mathrm{v})$ sucrose (final $\mathrm{pH} 6 \cdot 1)$. The polysaccharide was, however, definitely produced from $0.5(\mathrm{w} / \mathrm{v})$ sucrose medium (final $\mathrm{pH} 5 \cdot 5-5 \cdot 7$ ). The final $\mathrm{pH}$ value was always below 5 when the initial sucrose concentration exceeded $0 \cdot 75 \%$.

\section{The effect of various cultural conditions on growth and dextran production}

The results obtained, with Streptococcus bovis strains $1010 \mathrm{Y}$ and I are detailed in Table 3. It is evident that the presence of $\mathrm{CO}_{2}$ increased dextran yield, with or without $\mathrm{pH}$ control, although it seems to have had little effect on yields of organism. Maintaining the $\mathrm{pH}$ at 6.5-7 improved dextran yields in $\mathrm{CO}_{2}$ and gave an increased yield of organism. The best way so far found for fulfilling the above conditions, i.e. addition of $\mathrm{CaCO}_{3}$, gave the highest yields (nearly $80 \%$ conversion of available anhydro-glucose with strain I) obtained for each strain. The results however (Tables 1 and 3) do show considerable strain differences in the effect of $\mathrm{pH}$ control and $\mathrm{CO}_{2}$ on dextran production. Tween 80 did replace $\mathrm{CO}_{2}$ to some extent in stimulating dextran formation. Un-neutralized cultures incubated in $\mathrm{CO}_{2}$ for 1 or 3 days gave closely similar yields of organism and dextran. These results emphasize the need for $\mathrm{pH}$ control, as well as for $\mathrm{CO}_{2}$ in order to obtain optimum dextran production and cell multiplication.

Chromatographic examination of the cell-free supernatant fluid showed that,

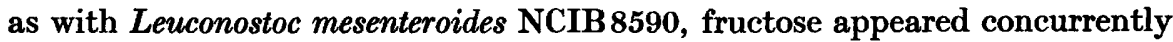
with dextran formation. The occurrence of other oligosaccharides in the cultures is discussed below.

\section{Structure of the dextran}

Structural studies were confined to the dextrans produced by the two strains of Streptococcus bovis, 1010 Y and I, used in the experiments described in Tables 2 and 3 and isolated from the cultures described in Table 1. Chromatograms of total hydrolysates showed a single reducing component chromatographically identical with glucose. There was no sign of any of the component sugars (galactose and rhamnose) of the capsular polysaccharide or of fructose. Chromatograms of partial hydrolysates, developed with solvent $(a)$, showed a single reducing component, $\boldsymbol{R}_{\text {olucose }}: \mathbf{0} \cdot 40$, chromatographically identical with iso-maltose produced by the partial hydrolysis of Leuconostoc (Betacoccus) arabinosaceous dextran (Barker et al. 1954): $\boldsymbol{R}_{\text {olucose }}$ : isomaltose $0 \cdot 40$; maltose 0.50 ; cellobiose 0.47 .

When sprayed with aniline hydrogen phthalate the disaccharide component gave the same brownish yellow colour as isomaltose. The component was also identical with isomaltose on chromatograms developed with solvent $(b)$ and by the benzylamine technique with solvent $(a)$. In this latter case the 
140

है

政

R. W. Bailey and A. E. Oxford

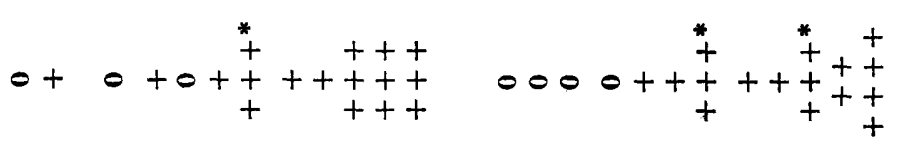

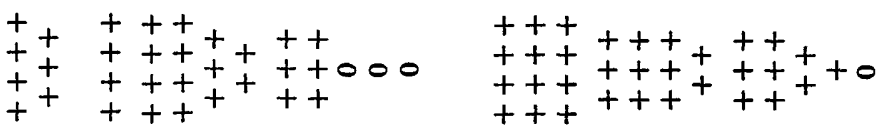

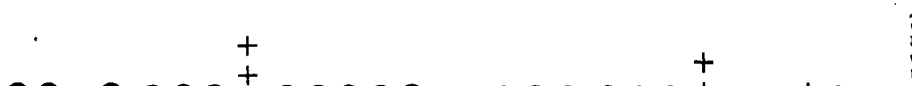

$000000+00+00$

它

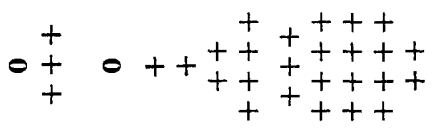

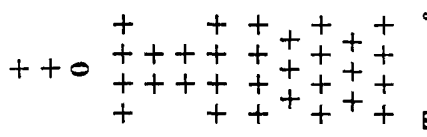

$\infty$

总

: $5: 0$

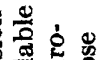

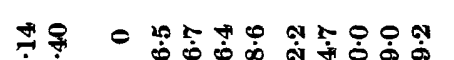

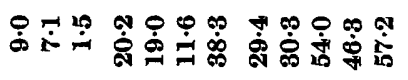

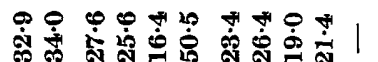

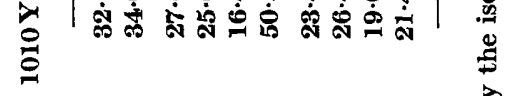

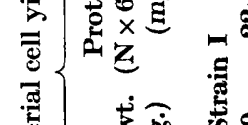

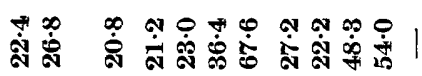

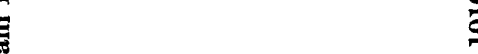

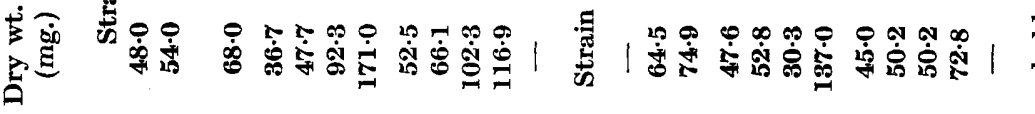

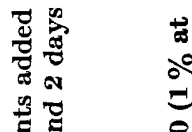

$\stackrel{\circ}{\stackrel{\circ}{\circ}}$

कि

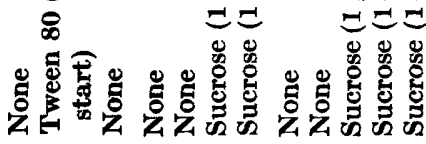

窟

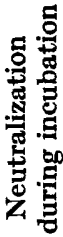

造

용

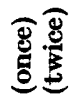

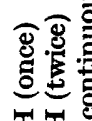

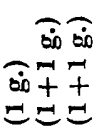

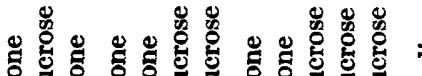

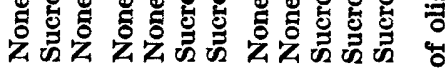

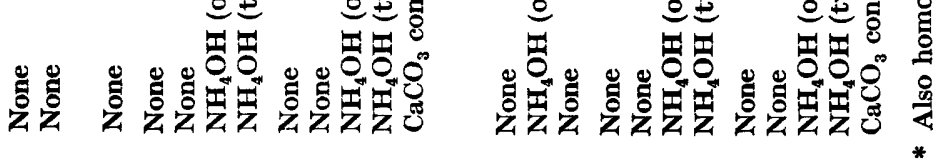

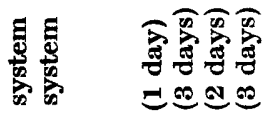

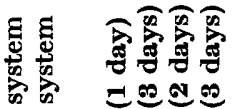

粒

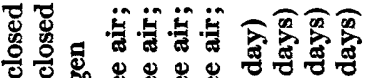

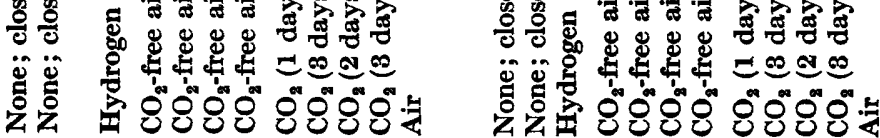


disaccharide had an $R_{F}$ value of 0.37 , cf. isomaltose $0 \cdot 37$, maltose $0 \cdot 44$, cellobiose $\mathbf{0} \cdot 42$ and glucose $0 \cdot 65$. A series of higher oligosaccharides was also present in the chromatograms from the partial hydrolysates and appeared to be identical with the series produced from the leuconostoc dextran (cf. Turvey \& Whelan, 1957). Using the benzylamine technique the trisaccharide of the series had an $\boldsymbol{R}_{F}$ value of $\mathbf{0 \cdot 2 0}$ (cf. isomaltotriose $\mathbf{0 \cdot 2 0}$ ).

Total acid hydrolyses of the dextrans from Streptococcus bovis strains I and $1010 \mathrm{Y}$ gave 97.0 and $96.0 \%$ conversion to glucose, respectively. Their optical rotations were: I dextran, $[\alpha]_{\mathrm{D}}^{20}+190^{\circ}(\mathrm{C} .0 \cdot 30)$ and $1010 \mathrm{Y} \cdot \operatorname{dextran},[\alpha]_{\mathrm{D}}^{20}+187^{\circ}$ (C. 0.36). During $96 \mathrm{hr}$. of oxidation, at $29^{\circ}$, with sodium metaperiodate dextrans $I$ and $1010 \mathrm{Y}$ consumed 2.00 and 1.94 mole periodate and produced 0.97 and $0.96 \mathrm{~mole}$ of formic acid/mole anhydro-glucose, respectively.

\section{Other oligosaccharides in the cultures}

In cultures producing dextran, in addition to fructose, a second reducing disaccharide was detected with the silver nitrate spray (see Table 3). This component had a value of $\boldsymbol{R}_{\text {olucose }}$ in solvent (a); 0.56 (cf. sucrose 0.70; isomaltose 0.44 ). It gave a positive ketose test with naphthoresorcinol and $\beta$-indolyl acetic acid sprays when they contained $2 \mathrm{~N}-\mathrm{HCl}$, but not when the acid was trichloroacetic acid. A small portion of this sugar was isolated on paper chromatograms and hydrolysed with oxalic acid $(1 \%, w / v)$ at $100^{\circ}$ for $2 \mathrm{hr}$. Paper chromatograms of the hydrolysate showed the presence of glucose and fructose and much unhydrolysed disaccharide.

Normally no sign of glucose could be detected on chromatograms of the culture fluid. Leuconostoc spp. produce definite traces of glucose because of their secretion of small amounts of a levansucrase. The complete absence of glucose suggests that Streptococcus bovis does not secrete such a levansucrase. In a few 3-day neutralized cultures, however (Table 3), a strong glucose component together with components corresponding to the isomaltose series of oligosaccharides (cf. Turvey \& Whelan, 1957) was present on the chromatograms.

\section{DISCUSSION}

The chromatographic identification of isomaltose as the sole disaccharide in the polysaccharide hydrolysates indicates that the polyglucosan is in fact dextran; this is confirmed by the positive optical rotation of the polysaccharide. The $[\alpha]_{\mathbb{D}}$ values, together with the periodate oxidation figures, are in agreement with the results that would be expected for a polymer closely resembling unbranched leuconostoc dextran (Barker et al. 1955). There is a real need for $\mathrm{CO}_{2}$ for maximum dextran production and presumably for dextransucrase secretion.

The appearance of an oligosaccharide concurrently with dextran production is not altogether unexpected as such sugars have been reported to occur in leuconostoc cultures (Stodola, Koepsell \& Sharpe, 1952). In this latter case they are believed to arise through fructose acting as an alternative glucosyl acceptor. Whether this is the case in Streptococcus bovis cultures awaits identification 
of the sugar. Detection of large amounts of glucose and the isomaltose series of oligosaccharides in occasional cultures was unexpected and an exception to the general complete absence of glucose. It may be suggested that in these cultures the organism had died and autolysis of the cells had released an invertase which had produced sufficient glucose to act as an alternative glucosyl acceptor. Glucose does act as such an acceptor to give oligosaccharides when added to leuconostoc cultures (Bailey, Barker, Bourne \& Stacey, 1955). As $S$. bovis is capable of fermenting sucrose without producing dextran presumably it contains an invertase.

Given the right conditions there can be little doubt that Streptococcus bovis is practically as good a dextran producer as Leuconostoc mesenteroides. Since $S$. bovis has a higher optimum growth temperature than $L$. mesenteroides the former produces dextran at a faster rate. It is tempting to relate the almost invariable $\mathrm{CO}_{2}$ requirement of $S$. bovis for good dextran production to the fact that this organism is in the main homofermentative (see Smith \& Sherman, 1942), whereas $L$. mesenteroides is heterofermentative; i.e. produces its own $\mathrm{CO}_{2}$ by hexose fermentation. One of our $S$. bovis strains (I), which had an absolute $\mathrm{CO}_{2}$ requirement for dextran production, required only $0.005 \mathrm{M}-\mathrm{HCO}_{3}^{-}$ to produce a good yield of dextran. It may well be that $S$. bovis strains with no such absolute $\mathrm{CO}_{2}$ requirement are ordinarily sufficiently heterofermentative to provide enough $\mathrm{CO}_{2}$ for limited dextran formation. The data of Smith \& Sherman (1942) show that $S$. bovis on the whole is not quite as good a lactic acid producer as $\boldsymbol{S}$. lactis. In the above cases, however, so little gas is produced that they would be reported as homofermentative in ordinary bacteriological tests with Durham tubes. Since most $S$. bovis strains seem able to use oxygen to some extent, it is essential to exclude air as far as possible if a real $\mathrm{CO}_{2}$ requirement for dextran production is to be demonstrated. It is worth noting that a closed culture flask half full of medium contains enough oxygen, in the air space, to yield $0.01 \mathrm{M}-\mathrm{HCO}_{3}^{-}$in the medium, provided that all of the oxygen is used for the complete oxidation of a carbohydrate to $\mathrm{CO}_{2}$.

If Streptococcus bovis dextransucrase has the same properties as leuconostoc dextransucrase, i.e. a $\mathrm{pH}$ optimum of $4 \cdot 0-4.5$ and a temperature optimum of 25-29 $9^{\circ}$ with destruction at $37^{\circ}$ (Bailey et al. 1957) then good dextran yields can only be obtained when the enzyme is continuously produced. This can only occur during continuous growth and all of the evidence (Table 3) indicates that $\mathrm{pH}$ control between 6 and 7 is necessary to ensure this. The properties of cell-free enzyme preparations are being investigated in order to clarify these points.

An important question is whether the effect of $\mathrm{CO}_{2}$ on dextran yield is due to $\mathrm{CO}_{2}$ gas in solution, the bicarbonate ion, or both. According to Umbreit, Burris \& Stauffer (1945) $\mathrm{HCO}_{\mathbf{3}}^{-}$cannot exist in solution at $\mathrm{pH}$ values below 5 , nor can $\mathrm{CO}_{3}^{--}$really exist below $\mathrm{pH}$ 8. Further, $\mathrm{H}_{2} \mathrm{CO}_{3}$ hardly exists at any $\mathrm{pH}$ value. Therefore in the $\mathrm{pH}$ range under study either or both $\mathrm{pCO}_{2}$ and $\mathrm{HCO}_{3}^{-}$may be implicated (cf. Loomis, 1957; Salisbury \& Vandemark, 1957; Whitehead, Jones \& Robertson, 1958; for instances of the control of biological 
phenomena by $\mathrm{pCO}_{2}$ ). We have not yet been able to settle this question. Streptococcus bovis (strain I) would not grow in a sucrose-containing nutrient medium containing $\mathrm{HCO}_{3}^{-}$through which a slow stream of $\mathrm{CO}_{2}$-free and $\mathrm{O}_{2}$-free hydrogen was bubbled for 1 day. The same batch of medium did however give good growth and dextran production in the same time in an anaerobic jar filled with $\mathbf{H}_{2}$. The culture which failed to grow in a stream of $\mathbf{H}_{2}$ later grew when air was admitted to the culture flask. Presumably the medium in the latter instance had an initial $\mathrm{pCO}_{2}$ of about $0.02 \%$ by volume $(0.00001 \mathrm{M})$ as have all undisturbed aqueous liquids in air at $30-40^{\circ}$ regardless of $\mathrm{pH}$ and $\mathrm{HCO}_{3}^{-}$concentration (cf. Loomis, 1957). It will obviously need much careful work to disentangle the effects of trace amounts of $\mathrm{CO}_{2}$ in initiating growth on the one hand and of the larger amounts which encourage dextran production on the other hand.

It must be granted that the role of $\mathrm{CO}_{2}$ in dextransucrase formation, if such a role exists, is not obvious at first sight. It may be a physical one since we have confirmed the observations of Dain et al. (1956) that Tween 80 can replace $\mathrm{CO}_{2}$ in anaerobic conditions in encouraging dextran formation. A second possibility is that $\mathrm{CO}_{2}$, at the higher concentration, inhibits all modes of sucrose fermentation operating with Streptococcus bovis save one, the dextransucrase pathway, which may be stimulated. This latter possibility seems to be the best working hypothesis at the moment (cf. Salisbury \& Vandemark, 1957). Although traces of $\mathrm{CO}_{2}$ are apparently necessary to initiate growth, higher concentrations do not increase it (see Table 3). An explanation of why $\mathrm{CO}_{2}$ stimulates the secretion of dextransucrase by $S$. bovis might throw considerable light on the mechanism of the secretion of trans-glucosidases of bacterial cells.

The authors wish to acknowledge the gift of a number of Streptococcus bovis cultures by Dr P. N. Hobson (Rowett Research Institute, Aberdeenshire). We are also indebted to Dr H. R. Whitehead (Dairy Research Institute, Palmerston North, New Zealand) for the opportunity of consulting his manuscript before publication and to Dr A. T. Johns, Director of this laboratory, for helpful discussion in preparing this paper. The sample of leuconostoc dextran used was originally prepared in Professor M. Stacey's laboratory (University of Birmingham) by one of us (R.W.B). The technical assistance of Miss $\mathrm{J}$. Michael is acknowledged.

\section{REFERENCES}

Bailey, R. W., Barker, S. A., Bourne, E. J. \& Stacey, M. (1955). Synthesis of oligosaccharides by growing cultures of Betacoccus arabinosaceous. Nature, Lond. $175,635$.

Bailey, R. W., Barker, S. A., Bourne, E. J. \& Stacey, M. (1957). The isolation and properties of the dextransucrase of Betacoccus arabinosaceous. J. chem. Soc. p. $\mathbf{3 5 3 0}$.

Barker, S. A., Bourne, E. J., Bruce, G. T., Neely, W. G. \& Stacey, M. (1954). The structure of a Betacoccus arabinosaceous dextran. J. chem. Soc. p. 2395.

Barker, S. A., Bourne, E. J., James, A. E., Neely, W. B. \& Stacey, M. (1955). The structure of a modified Betacoccus arabinosaceous dextran. J. chem. Soc. p. 2096. 
Bayly, R. J. \& Bourne, E. J. (1953). A new method for the paper chromatography of oligosaccharides. Nature, Lond. 171, 385.

Dain, J. A., Neal, A. L. \& Seeley, H. W. (1956). The effect of carbon dioxide on polysaccharide production by Streptococcus bovis. J. Bact. 72, 209.

Henre, E. J. \& NeILl, J. M. (1946). Formation of serologically active dextran by streptococci from subacute bacterial endocarditis. J. exp. Med. 83, 145.

Heyrovsky, A. (1956). A new detection method for ketose sugars. Biochim. Biophys. Acta, 21, 180.

Hobson, P. N. \& MacPherson, M. J. (1954). Some serological and chemical studies on materials extracted from an amylolytic streptococcus from the rumen of the sheep. Biochem. J. 57, 145.

Hungate, R. E. (1957). Micro-organisms in the rumen of cattle fed on a constant ration. Canad. J. Microbiol. 3, 289.

Hungate, R. E., Fletcher, D. W., Dougherty, R. W. \& Barrentine, B. F. (1955). Microbial activity in the bovine rumen: its measurement and relation to bloat. Appl. Microbiol. 3, 161.

Jeanes, A. R. \& Wilham, C. A. (1952). Periodate oxidation of dextrans. J. Amer. chem. Soc. 74, 5339.

Jermyn, M. A. \& Ishenwoon, F. A. (1949). Improved separation of the sugars on the paper partition chromatogram. Biochem. J. 44, 402.

Koepsell, H. J. \& Tsuchiya, H. M. (1952). Enzymatic synthesis of dextran. $J$. Bact. 63, 293.

Looms, W. F. (1957). Sexual differentiation in Hydra. Science, 126, 735.

Macpherson, M. J. (1953). Isolation and identification of amylolytic streptococci from the rumen of the sheep. J. Path. Bact. 66, 95.

MANN, S. O., Masson, F. M. \& OXFord, A. E. (1954). Facultative anaerobic bacteria from the sheep's rumen. J. gen. Microbiol. 10, 142.

MANN, S. O. \& OXFord, A. E. (1955). Relationships between viable saccharolytic bacteria in rumen and abomasum of the young calf and kid. J.gen. Microbiol. $12,140$.

Niven, C. F., Smiley, K. L. \& Sherman, J. M. (1941). The polysaccharide synthesized by Streptococcus salivarius and Streptococcus bovis. J. biol. Chem. 140, 105.

Partridge, S. M. (1948). Filter paper partition chromatography of sugars. Biochem. J. 42, 238.

Partridge, S. M. (1949). Aniline hydrogen phthalate as a spraying reagent for chromatography of sugars. Nature, Lond. 166, 443.

Pirt, S. J. \& Whelan, W. J. (1951). The determination of starch by acid hydrolysis. J. Sci. Fd Agric. 2, 224.

Roe, J. H. (1954). The determination of dextran in blood and urine with anthrone reagent. J. biol. Chem. 208, 889.

Salisbury, G. W. \& VANDemark, N. L. (1957). Sulfa compounds in reversible inhibition of sperm metabolism by carbon dioxide. Science, 126, 1118.

Sevag, M. G., Lackman, D. B. \& Smolens, J. (1938). The isolation of the components of streptococcal nucleoproteins in serologically active form. J. biol. Chem. $124,425$.

Shaffer, P. A. \& Hartmann, A. F. (1921). The iodometric determination of copper and its use in sugar analyses. J. biol. Chem. 45,365 .

Smith, P. A. \& Sherman, J. M. (1942). The lactic acid fermentation of streptococci. J. Bact. 43, 725.

Stodola, F. H., Koepsell, H. J. \& Sharpe, E. S. (1952). A new disaccharide produced by $L$. mesenteroides. J. Amer. chem. Soc. 74, 3202.

Topley \& Wilson's Principles of Bacteriology and Immunity (1946). 3rd ed. p. 600. Edited by Wilson, G. S. \& Miles, A. A. London: Edward Arnold and Co.

Trevelyan, W. E., Proctor, D. P. \& Harrison, J. S. (1950). Detection of sugars on paper chromatograms. Nature, Lond. 166, 444. 
Turvey, J. R. \& Whelan, W. J. (1957). Preparation and characterization of the isomaltodextrins. Biochem. J. 67, 49.

Umbreit, W. W., Burris, R. H. \& Stauffer, J. F. (1945). Manometric Techniques and Related Methods for the Study of Tissue Metabolism. Minneapolis: Burgess Publishing Co.

Whitehead, H. R., Jones, P. A. \& Robertson, P. S. (1958). The influence of carbon dioxide on the growth of lactic streptococci. J. Dairy Res. (in Press).

(Received 3 February 1958) 